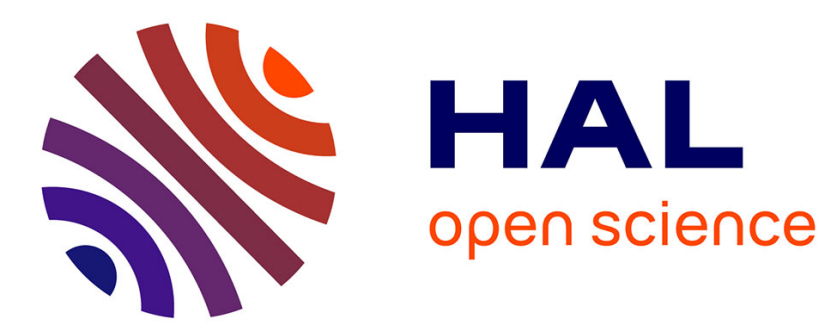

\title{
Effect of substitutional Ni atoms on the Snoek relaxation in ferrite and martensite Fe-C alloys: An atomistic investigation
}

Liangzhao Huang, Philippe Maugis

\section{To cite this version:}

Liangzhao Huang, Philippe Maugis. Effect of substitutional Ni atoms on the Snoek relaxation in ferrite and martensite Fe-C alloys: An atomistic investigation. 2021. hal-03470006

\section{HAL Id: hal-03470006 \\ https://hal-amu.archives-ouvertes.fr/hal-03470006}

Preprint submitted on 8 Dec 2021

HAL is a multi-disciplinary open access archive for the deposit and dissemination of scientific research documents, whether they are published or not. The documents may come from teaching and research institutions in France or abroad, or from public or private research centers.
L'archive ouverte pluridisciplinaire HAL, est destinée au dépôt et à la diffusion de documents scientifiques de niveau recherche, publiés ou non, émanant des établissements d'enseignement et de recherche français ou étrangers, des laboratoires publics ou privés. 


\title{
Effect of substitutional $\mathrm{Ni}$ atoms on the Snoek relaxation in ferrite and martensite Fe-C alloys: an atomistic investigation
}

\author{
Liangzhao Huang $^{\mathrm{a}, *}$, Philippe Maugis ${ }^{\mathrm{a}}$ \\ ${ }^{a}$ Aix Marseille University, CNRS, IM2NP, Marseille, France
}

\begin{abstract}
Quantitative simulations of the carbon-induced internal friction in ferrite/martensite Fe-C and Fe-Ni-C alloys are performed by combining a mean-field elastic model and the atomistic kinetic Monte Carlo based on a pair interaction model to describe the composition-dependent carbon migration. The simulation is validated by experimental data and a thermo-kinetic theory. Our results predict that (i) additional peaks occur in the internal friction profiles of $\mathrm{Fe}-\mathrm{C}$ and Fe-Ni-C due to C-C and Ni-C pair interactions; (ii) the Ni-alloying shifts the internal friction peak to lower temperature than in Fe-C alloys; (iii) the peak temperature is not simply related to the most frequent carbon jumps during the relaxation process; (iv) the internal friction behavior in martensite depends on the excitation direction with respect to the carbon ordering direction.
\end{abstract}

Keywords: Anelastic behavior, Internal friction, Carbon steels, Monte Carlo simulation, Mean-field modeling

\section{Introduction}

Carbon (C) plays a relevant role in the ageing of both ferrite and ferrous martensite, due to the formation of carbides [1], the carbon segregation on structural defects $[2,3]$, the hardening and embrittlement effects $[4,5]$, etc. A good understanding of the carbon properties is critical to predict the material behavior. Internal friction (IF) measurement is one of the common ways to study the carbon diffusion $[6,7,8,9,10,11,12,13]$.

Carbon atoms are interstitial solutes sitting on the octahedral $(\mathrm{O})$ sites in the body-centered cubic (bcc) iron ( $\mathrm{Fe})$. They migrate from one stable site to another through the tetrahedral $(\mathrm{T})$ site. The host matrix is deformed by carbon atoms. Following the deformation direction, one can identify three sets of non-equivalent $\mathrm{O}$ and $\mathrm{T}$ sites, respectively. The overall strain of the crystal results not only from the externally applied stress but also from the carbon distribution. Since the applied stress field energetically favors one of the three sets of stable sites (i.e., the so-called Zener ordering [14]), carbon atoms redistribute through atomic jumps towards favored stable sites. This redistribution modifies the carbon-induced strain field. The latter in return interacts with the carbon atoms and affects the energy level of both stable and transition sites. Therefore, the strain response of the crystal to a cycling stress is not instantaneous because of the carbon redistribution. The delay of the total strain response characterizes the loss of the elastic energy during this relaxation process (i.e.,

\footnotetext{
*Corresponding author

Email addresses: huang.liangzhao@outlook.com (Liangzhao Huang), philippe.maugis@im2np.fr (Philippe Maugis)
}

Snoek relaxation $[15,16])$, corresponding to the Snoektype IF of the material.

IF is sensitive to the density of existing defects in the crystal [6], as for instance carbon atoms strongly interact with the dislocation in the Cottrell atmospheres, while few solute carbons are left in the perfect crystal. As a preliminary study, the present article focuses on the case where the defect density is low such that IF is not affected by the carbon-defect interactions. Therefore, our study is restricted to the investigation of the Snoek relaxation. The latter can be biased by alloying elements, which modifies, on one hand, the elastic properties of the crystal, and on the other hand, the carbon migration properties due to solute-carbon pair interactions [12]. In general, substitutional solute atoms lowered the Snoek peak height in bcc Fe-C alloys [17, 12]. The case of nickel (Ni)-alloying is of particular interest, notably for maraging steels conception [18]. Experimental studies showed that the Nialloying lowered the IF amplitude and the peak temperature in ferrite $[19]$ and martensite $[6,9,10]$. A full investigation of the Ni-alloying effect on the IF behaviors should be accomplished by simulation approaches. Atomistic kinetic Monte Carlo (AKMC) simulations have been applied to compute the IF in ferrite Fe-C [20, 21] and Fe-Cr-C alloys [22]. However, close studies are still lacking for ferrite Fe-Ni-C alloy. Moreover, an reliable approach to simulate IF measurement in martensite is still in need. Recent studies based on a mean-field elastic model provided an efficient approach to describe the kinetics and thermodynamics of carbon atoms in ferrous martensite [23, 24]. Combining the mean-field approach and the AKMC simulation provides a possible way to compute the IF in martensite Fe- 


\section{Ni-C alloys.}

The objective of this work is to quantitatively simulate IF measurements in ferrite/martensite Fe-C and Fe-Ni-C model alloys based on an atomistic approach, which is reflected in the paper organization. In Section 2, we will introduce the mean-field elastic model and the pair interaction model used to reproduce the local environmentdependent carbon migration in tetragonal crystal. Then, in Section 3, we will present two possible methods to simulate the IF measurements: an efficient thermo-kinetic model for specific systems and a general approach using AKMC. In Section 4, we will discuss our results and extract from them some insights on the available experimental data and the Ni-alloying effect on the IF profile in ferrite and martensite Fe-C model alloys. Finally, a summary, concluding remarks, and perspectives will be given in Section 5 .

\section{Diffusion model}

The three sets of non-equivalent octahedral (resp. tetrahedral) sites are characterized by the force dipole tensor $\boldsymbol{P}_{i=1,2,3}^{\mathrm{O}}$ (resp. $\boldsymbol{P}_{j=1,2,3}^{\mathrm{T}}$ ). Assuming that the carbon atoms are randomly distributed in space, the resulting strain field $(\boldsymbol{\epsilon})$ is given by a mean-field approach $[25,23]$ and is written as:

$$
\epsilon=S(\sigma+p)
$$

where $\boldsymbol{S}$ is the elastic compliance tensor, $\boldsymbol{\sigma}$ is the stress tensor, and $\boldsymbol{p}$ is the average dipole tensor which is given by

$$
\boldsymbol{p}=\frac{1}{V_{0}} \sum_{i=1}^{3} c_{i} \boldsymbol{P}_{i}^{\mathrm{O}}
$$

with $V_{0}$ the atomic volume of the lattice and $c_{i}$ is the site fraction defined as the ratio between the number of carbon atoms sitting on the $i$-octahedral site and the number of bcc lattice sites. The migration enthalpy of a carbon atom from octahedral site $i$ through the tetrahedral site $j$ is expressed as function of the strain tensor and the elastic dipole tensors [26, 27, 28, 23]:

$$
H_{i / j}^{\mathrm{m}}=H_{0}^{\mathrm{m}}-\left(\boldsymbol{P}_{j}^{\mathrm{T}}-\boldsymbol{P}_{i}^{\mathrm{O}}\right): \boldsymbol{\epsilon}
$$

where $H_{0}^{\mathrm{m}}$ is the migration enthalpy of the stress-free bcc Fe crystal. This equation implies that the carbon diffusion enthalpy depends on both the applied stress $\boldsymbol{\sigma}$ and the carbon distribution.

In systems with high carbon or nickel concentration, the carbon migration enthalpy depends also on the local chemical environment. A pair interaction model is applied to describe the variation of the carbon migration barriers with the local environments. The C-C and Ni-C pairwise interactions are given by the $a b$ initio calculations in Refs. [29] and [30], respectively. These interactions are in- cluded in the carbon jump frequency:

$\omega_{i / j}=\nu_{0} \exp \left[-\frac{H_{i / j}^{\mathrm{m}}+\left(E_{\mathrm{C}-\mathrm{C}}^{\mathrm{T}}-E_{\mathrm{C}-\mathrm{C}}^{\mathrm{O}}\right)+\left(E_{\mathrm{Ni}-\mathrm{C}}^{\mathrm{T}}-E_{\mathrm{Ni}-\mathrm{C}}^{\mathrm{O}}\right)}{k_{\mathrm{B}} T}\right]$,

where $k_{\mathrm{B}}$ is the Boltzmann constant, $T$ is temperature, $\nu_{0}$ is the attempt frequency that is assumed to be strain- and composition-independent, and

$$
E_{\alpha-\mathrm{C}}^{\mathrm{T}}=\sum_{k} z_{k} E_{\alpha-\mathrm{C}}^{k}(\mathrm{OT}), E_{\alpha-\mathrm{C}}^{\mathrm{O}}=\sum_{k} z_{k} E_{\alpha-\mathrm{C}}^{k}(\mathrm{OO})
$$

where $z_{k}$ is the number of atom $\alpha=\mathrm{C}, \mathrm{Ni}$ at the $k$-th nearest-neighbour shell of the considered carbon atom, and $E_{\alpha-\mathrm{C}}^{k}(\mathrm{OT})\left(\right.$ resp. $\left.E_{\alpha-\mathrm{C}}^{k}(\mathrm{OO})\right)$ is the pairwise interaction between an atom $\alpha$ on a octahedral site and a carbon atom on a tetrahedral (resp. octahedral) site at the $k$-th nearestneighbour distance.

The material parameters are assumed to be independent of temperature in the range of interest (250-350 K). In order to evaluate the Ni-alloying effect on IF, we compare the simulation results using two sets of the elastic parameters computed from first principles in Ref. [30] (cf. Tab. 1). The attempt frequency and the stress-free carbon migration enthalpy are obtained by fitting the data in Ref. [31]: $\nu_{0}=149 \mathrm{THz}$ and $H_{0}^{\mathrm{m}}=0.872 \mathrm{eV}$.

Table 1: Elastic parameters of Fe and Fe-25Ni (at.\%) that are used in the simulations of IF. These results were computed from first principles in Ref. [30]

\begin{tabular}{lcc}
\hline \hline Materials & Fe & Fe-25Ni \\
\hline Lattice parameter $[\AA]$ & 2.831 & 2.851 \\
$S_{11}\left[\mathrm{GPa}^{-1}\right]$ & 0.00555 & 0.01020 \\
$S_{12}\left[\mathrm{GPa}^{-1}\right]$ & -0.00191 & -0.00396 \\
$S_{44}\left[\mathrm{GPa}^{-1}\right]$ & 0.00100 & 0.00874 \\
$P^{\mathrm{O}}$, disfavored site $[\mathrm{eV}]$ & 9.1 & 4.9 \\
$P^{\mathrm{O}}$, favored site $[\mathrm{eV}]$ & 18.2 & 11.8 \\
$P^{\mathrm{T}}$, disfavored site $[\mathrm{eV}]$ & 14.3 & 9.8 \\
$P^{\mathrm{T}}$, favored site $[\mathrm{eV}]$ & 5.0 & 2.75 \\
\hline \hline
\end{tabular}

\section{Calculation methods for the internal friction}

We consider a system submitted to a sinusoidal (001)[110] shear stress at selected frequency $f$ such that $\sigma_{22}=-\sigma_{11}=\sigma_{0} \sin (2 \pi f t)$. The crystal response is a sinusoidal shear strain $\epsilon(t)$. The time lag between stress and strain corresponds to the energy loss of the system, i.e., the internal friction (denoted by $Q^{-1}$ ). The latter is computed as the fraction energy loss per cycle:

$$
Q^{-1}=\frac{1}{2 \pi} \frac{\Delta W}{W_{\max }}
$$

where $\Delta W=\int \boldsymbol{\sigma}: d \boldsymbol{\epsilon}$ is the energy loss per cycle and $W_{\max }$ is the maximum elastically stored energy per unit 
volume during a cycle. Note that if carbon atoms are diffusing in low-carbon Fe, $Q^{-1}$ follows a Debye curve [32]:

$$
Q^{-1}=\Delta \frac{\omega \tau}{1+(\omega \tau)^{2}}
$$

where $\omega=2 \pi f, \tau$ is the relaxation time, and $\Delta$ is the relaxation strength. It is shown in Ref. [21] that both $\tau$ and $\Delta$ depend on the material parameters, carbon content and temperature. At low carbon content, the relaxation time $\tau$ has a simplified expression [33, 22, 21]:

$$
\tau=\left(6 \nu_{0}\right)^{-1} \exp \left(\frac{H_{0}^{\mathrm{m}}}{k_{\mathrm{B}} T}\right) .
$$

$Q^{-1}$ reaches its maximum when $\tau=1 / \omega$. According to Eq. (8), for a given relaxation frequency ( $f$ or $\omega)$, the temperature corresponding to the maximum $Q^{-1}$ writes

$$
T_{\max }=\frac{H_{0}^{\mathrm{m}}}{k_{\mathrm{B}} \ln \left(6 \nu_{0} / \omega\right)} .
$$

Later in this section, we will present two methods to calculate the internal friction: the atomistic Kinetic Monte Carlo (AKMC) simulation and the thermo-kinetic (TK) model.

\subsection{Atomistic kinetic Monte Carlo simulations}

AKMC simulations based on the residence-time algorithm are performed on the body-centered cubic (bcc) lattice with the octahedral sites. Details of the method can be found in Ref. [23]. About 6000 carbon atoms are inserted in the lattice. The size of the simulation box is adjusted by the atomic fraction of carbon atoms. The number of simulation steps is adjusted such that the number of stress cycles is larger than 50. The applied stress amplitude is set to $300 \mathrm{MPa}$. The latter is a relatively high value compared with the experimental usage, but technically necessary to overcome the high fluctuations present in the finite-size simulation box [21]. The site fractions of the carbon atoms $\left(c_{i=1,2,3}\right)$ are measured after each atomic jump. The resulting strain evolution $\epsilon(t)$ is given by Eq. (1).

\subsection{Thermo-kinetic model}

In a Ni-free lattice with a low carbon concentration, the $\mathrm{C}-\mathrm{C}$ and Ni-C pair interactions can be neglected. In this case, only three non-equivalent carbon migration barriers are left: $\omega_{1 / 2}, \omega_{2 / 3}$, and $\omega_{3 / 2}$. The TK model is thus characterized by the following master equation of the site fraction [21]:

$$
\frac{\mathrm{d} c_{i}}{\mathrm{~d} t}=2 \sum_{k \neq i} J_{k \rightarrow i}, \quad i=1,2,3,
$$

where $J_{k \rightarrow i}=c_{k} \omega_{k / j}-c_{i} \omega_{i / j}(i \neq j \neq k)$ is the net flux of carbon atoms from octahedral site $k$ to octahedral site $i$ via the tetrahedral site $j$. High-accuracy Runge-Kutta integration of the coupled rate equations (10) is performed to obtain the evolution of the site fractions. The strain response $\epsilon(t)$ is given by Eq. (1).

\section{Results and discussions}

\subsection{IF in ferrite $\mathrm{Fe}-\mathrm{C}$ and $\mathrm{Fe}-\mathrm{Ni}-\mathrm{C}$}

In this section, we consider the IF in ferrite $\mathrm{Fe}-\mathrm{C}$ alloy and study the variation of the IF profile after the introduction of 25 at. $\% \mathrm{Ni}$ in the alloy. Note that the lowtemperature $(<600 \mathrm{~K})$ equilibrium lattice structure of $\mathrm{Fe}-$ $\mathrm{Ni}$ is still an open question; and it is difficult to reach stable equilibrium at the investigated temperatures $(\sim 300 \mathrm{~K})$ due to very slow interdiffusion between $\mathrm{Fe}$ and $\mathrm{Ni}$ [34]. Moreover, the lattice structure of Fe-Ni is metastable because it depends on the heat treatment given to the alloy $[35,36,37]$. The reported measurements in Ref. [36] of the lattice parameters of $\mathrm{Fe}-\mathrm{Ni}$ quenched from high temperature showed that quenched Fe-25at.\%Ni is of bcc structure. We assume that low-carbon Fe-25Ni-C has the same lattice structure. Since the carbon concentration is relatively low in the investigated alloy $(\leq 0.01$ at. $\%$ in the present work), the $\mathrm{C}-\mathrm{C}$ pair interactions are neglected in the simulation.

\subsubsection{Simulation benchmark}

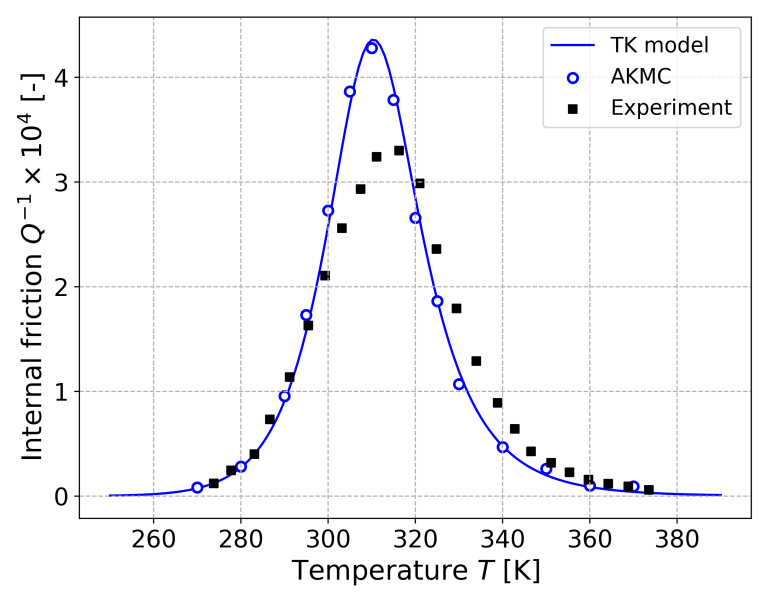

Figure 1: Comparison between the carbon Snoek relaxation profiles in bcc Fe-C alloy obtained by AKMC simulations, thermo-kinetic model, and experiment of Weller for diamonds [33]. The total carbon site fraction $\left(\sum_{i=1}^{3} c_{i}\right)$ is 20 at.ppm and the oscillation frequency is $1 \mathrm{~Hz}$.

As a test to validate the simulation approach of the Snoek relaxation proces, we compare the simulated internal friction profiles respectively obtained by AKMC simulation and TK model with the experimental one obtained by Weller [33] (cf. Fig. 1). We convert the internal friction profile computed for a single crystal to the one for polycrystal via the Reuss averaging method [38, 32]. The profile given by AKMC simulation is in excellent agreement with the one computed from TK model. Both simulation approaches predict that the IF peak is around $4.3 \times 10^{-4}$ at $310 \mathrm{~K}$, while the experimental results shows that the IF peak height is lower (about $3.3 \times 10^{-4}$ ) and at higher temperature (about $318 \mathrm{~K}$ ). However, the agreement between 
the two simulated profiles and the experimental one is satisfactory, which justifies the validity of AKMC simulation and TK model.

\subsubsection{Ni-alloying effect on the IF in ferrite $\mathrm{Fe}$ - $\mathrm{C}$ alloy}

In order to highlight the $\mathrm{Ni}$ effect on the IF in ferrite $\mathrm{Fe}-$ $\mathrm{C}$ alloy, we compare the IF profiles in Fe-0.01C (at.\%) and Fe-25Ni-0.01C (at.\%) alloys [cf. Fig. 2-(a)]. Here again, the IF profiles simulated by AKMC simulation and TK model are in excellent agreement in Fe-0.01C alloy. The peak height is around $55 \times 10^{-4}$ and the peak position is at $310 \mathrm{~K}$. In Fe-25Ni-0.01C, the carbon migration barriers depend on the local environment due to $\mathrm{Ni}-\mathrm{C}$ pair interactions. Therefore, the present TK model [Eq. (10)] is not applicable to simulate the Snoek relaxation process, and only the AKMC simulation results are presented. The introduction of 25 at.\% $\mathrm{Ni}$ in $\mathrm{Fe}-0.01 \mathrm{C}$ leads to a decrease of the peak height (from $55 \times 10^{-4}$ to around $34 \times 10^{-4}$ ) and the peak temperature (from $310 \mathrm{~K}$ to around $300 \mathrm{~K}$ ). In addition, the half peak width in $\mathrm{Fe}-25 \mathrm{Ni}-0.01 \mathrm{C}$ is larger than that in Fe-0.01C.

Note that the material parameters (i.e., the stiffness tensors and the elastic dipole tensors) are modified in $\mathrm{Ni}$ alloyed Fe [30]. This modification should be responsible for the decrease of the peak height as the relaxation strength $\Delta$ is sensitive to the material parameters [21]. Moreover, as mentioned before, the carbon migration barriers are largely modified by $\mathrm{Ni}-\mathrm{C}$ pair interactions: in $\mathrm{Fe}-0.01 \mathrm{C}$, the carbon migration enthalpy is very close to the stressfree one $\left(H_{0}^{\mathrm{m}}\right)$ because $\mathrm{C}-\mathrm{C}$ pair interactions are negligible and the applied stress leads to very small modification of the migration barrier; in Fe-25Ni-0.01C, the carbon migration enthalpy does not have a single value but performs a value spectrum, as presented in Fig. 2-(b). This is obtained from AKMC simulation: after each selected carbon jump, the corresponding migration enthalpy and the residence time between the current and next jumps are recorded; at the end of simulation, we sum up the recorded residence time corresponding to each value range of the migration enthalpy, and then the total residence time of each range is normalized by the total simulation time. The carbon migration enthalpy is smaller than $H_{0}^{\mathrm{m}}$ most of the time. This is because the repulsive Ni-C pair interactions lower the carbon migration barriers. The maximum of the spectrum is at $H_{0, \max }^{\mathrm{m}} \simeq 0.77 \mathrm{eV}$, and the time average enthalpy is $H_{0 \text {,ave }}^{\mathrm{m}}=0.71 \mathrm{eV}$. Assuming that the carbon diffusion can be described by a single effective migration enthalpy (denoted by $H_{0 \text {,eff }}^{\mathrm{m}}$ ), the latter should be related to the peak temperature by Eq. (9). According to the profile simulated by AKMC, the peak temperature is around $300 \mathrm{~K}$, and the corresponding value of $H_{0, \text { eff }}^{\mathrm{m}}$ is around $0.84 \mathrm{eV}$. The latter corresponds neither to $H_{0, \text { max }}^{\mathrm{m}}$ nor to $H_{0 \text {,ave }}^{\mathrm{m}}$, although these three values are all smaller than the $\mathrm{Ni}$-free value, $H_{0}^{\mathrm{m}}$.

On the other hand, a plateau of the migration enthalpy $(\sim 0.6 \mathrm{eV})$ occurs in the spectrum of Fig. $2-(\mathrm{b})$. To explain the shape of this spectrum, we focus on how the Ni-C pair interaction modifies the carbon migration enthalpy. Considering a bcc lattice with an iron atom in the center, as presented in Fig. 2-(c), two of the eight remaining lattice sites should be occupied by $\mathrm{Ni}$ atoms on average in $\mathrm{Fe}-$ $25 \mathrm{Ni}-0.01 \mathrm{C}$ alloy. For a carbon atom jumping from position $i$ to $j$, we identify four energetically non-equivalent sets of Ni position: $\alpha, \beta, \gamma$, and $\delta$. The carbon migration enthalpies corresponding to different combinations of the two Ni atom positions are listed in Fig. 2-(d). According to the pair interaction data, the $\mathrm{Ni}$ atom repulsively interacts with the $\mathrm{C}$ atom in the octahedral site, while it hardly interacts with the $\mathrm{C}$ atom in the transition state. Moreover, the Ni-C repulsion is important only when the $\mathrm{Ni}-\mathrm{C}$ distance is at the 1 st nearest neighbor $(1-\mathrm{NN})$ or 2 $\mathrm{NN}$ shells. Ni-C interactions sharply decrease beyond the $2-\mathrm{NN}$ shell. Therefore, the carbon atom is considered to be close to the $\mathrm{Ni}$ atom when the $\mathrm{Ni}-\mathrm{C}$ distance is smaller than or equal to 2-NN distance; otherwise, the carbon atom is considered to be far from the Ni atom. Since the migration enthalpy is independent of the final state, we only discuss how the migration enthalpy varies with the initial $\mathrm{C}$ position with respect to $\mathrm{Ni}$ atoms in the lattice. When the initial $\mathrm{C}$ position is close to $\mathrm{Ni}$ atoms $(\leq 2-\mathrm{NN}$ distance), the migration enthalpies $(0.43-0.73 \mathrm{eV})$ are much smaller than those for initial $\mathrm{C}$ position far from Ni atoms (0.78$0.87 \mathrm{eV})$. The former contribute to the enthalpy plateau at around $0.6 \mathrm{eV}$ in the enthalpy spectrum, while the latter contribute to the peak at around $0.8 \mathrm{eV}$. The latter amplitude is higher than the former one because most of the $\mathrm{C}$ atoms preferentially stay far from $\mathrm{Ni}$ atoms due to important Ni-C repulsion at small distances. Even though an enthalpy peak and a enthalpy plateau are shown in the enthalpy spectrum, only one peak occurs in the IF profile. Another IF peak may occur at a temperature lower than the investigated ones. According to Eq. (9), this temperature is around $210 \mathrm{~K}$. Note that the residence time of each AKMC step should be much smaller than the period time of the excitation so that the statistic is enough to precisely calculate the IF in a cycle. However, at very low temperature $(<250 \mathrm{~K})$, carbon diffusion is so slow that numerous carbon atoms $\left(>10^{4}\right)$ should be introduced in the simulation box in order to reduce the average residence time to a reasonable value. In this case, the computational cost of AKMC simulations is unrealistic.

The IF profile in Fe-25Ni-0.01C does not follow the Debye equation: it is impossible to quantitatively well fit this profile using Eq. (7). This is because the IF profile does not result from a single carbon migration barrier but a complex spectrum. Therefore, it may correspond to a superposition of multiple Debye curves [39, 40]. This explains why the IF profile in Fe-25Ni-0.01C is wider than the one in Fe-0.01C. However, the migration enthalpy related to each Debye curve does not simply correspond to one of the carbon jumps in the enthalpy spectrum, but a complex function of several representative jumps [39, 40]. This justifies why the migration enthalpy related to the IF peak is different from the one of the most frequent atomic 


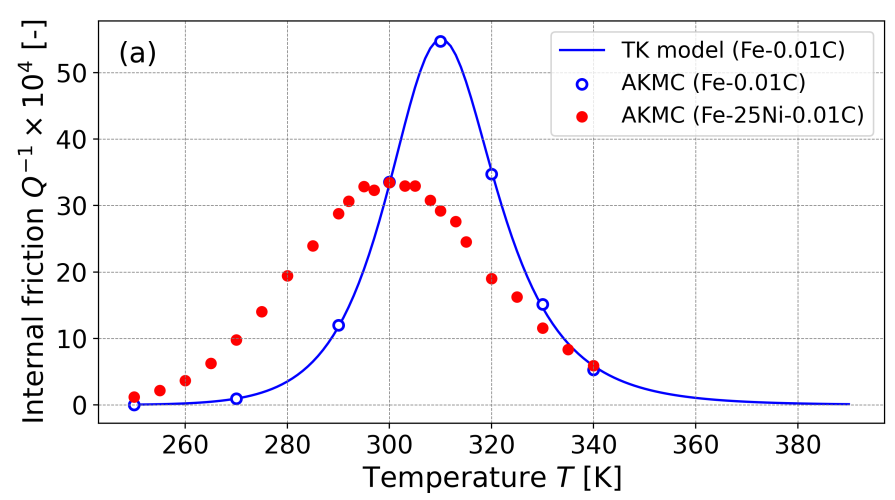

(c)

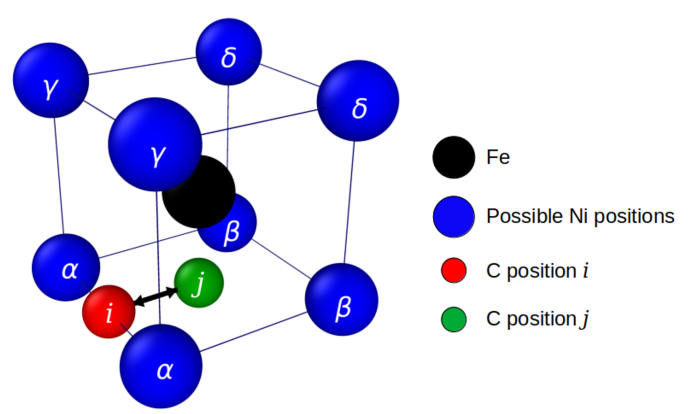

(b)

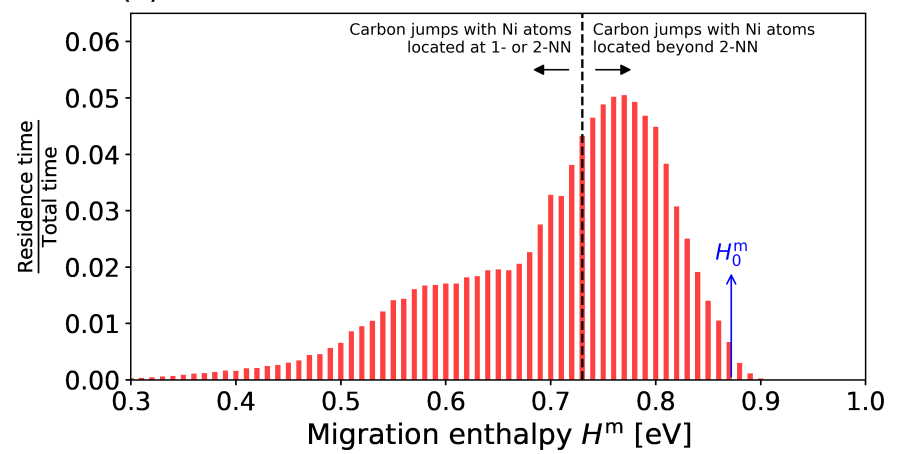

(d)

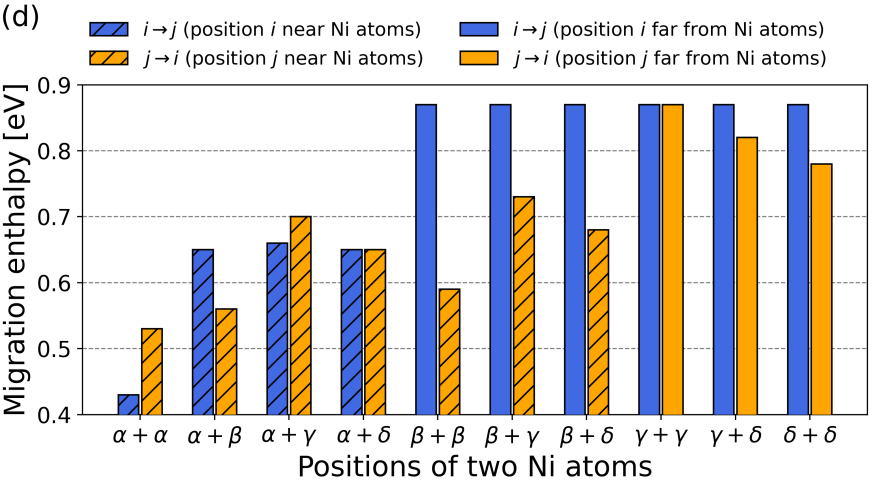

Figure 2: (a) Snoek relaxation profiles in Ni-free and Ni-alloyed bcc Fe-C ferrite. (b) spectrum of carbon migration enthalpy in Fe-Ni-C alloy at $300 \mathrm{~K}$ obtained from AKMC simulation. In (a) and (b), the Ni site fraction in Fe-Ni-C alloy is set to 25 at. $\%$, the total carbon site fraction $\left(\sum_{i=1}^{3} c_{i}\right)$ is set to 0.01 at.\%, and the oscillation frequency is $1 \mathrm{~Hz}$. (c) Possible Ni atom positions in a bcc Fe-Ni-C lattice: Fe atom is set to be in the center of lattice; $\alpha, \beta, \gamma$, and $\delta$ are four energetically non-equivalent sites for Ni atoms with respect to the carbon jumps from site $i$ to $j$; for the alloy Fe-25Ni-C, two of the eight remaining lattice sites are occupied by Ni atoms on average. (d) Carbon migration enthalpies for transition $i \leftrightarrow j$ corresponding to different combinations of two $\mathrm{Ni}$ atom positions.

jumps identified from the migration enthalpy spectrum.

\subsubsection{Comparison with experiment in ferrite}

An experimental study of the substitutional Ni effect on the Snoek peak in bcc Fe-0.07C (at.\%) alloys is reported in Ref. [19]. However, a direct comparison between the reported experimental IF profiles and those from our simulation is not very meaningful because the investigated compositions of $\mathrm{Ni}$ and $\mathrm{C}$ are quite different: $\mathrm{Fe}-0.07 \mathrm{C}$ and $\mathrm{Fe}-$ $5 \mathrm{Ni}-0.07 \mathrm{C}$ in Ref. [19] versus Fe-0.01C and Fe-25Ni-0.01C in the present work. Therefore, we choose to compare the relative change of the IF profile parameters due to the addition of $\mathrm{Ni}$, which are presented in Tab. 2. Our simulation results are qualitatively consistent with the experimental ones: the addition of $\mathrm{Ni}$ (i) reduces the carbon Snoek peak height; (ii) increases the half peak width; and (iii) shifts the peak temperature to a lower value. The increase of the half peak width and the shift of the peak temperature induced by the addition of 25 at. $\% \mathrm{Ni}$ in our simulation is greater than those induced by the addition of 5 at. $\%$ $\mathrm{Ni}$ in the experiment. By normalizing these quantities by the Ni composition in the alloy, we obtain a quantitative agreement between the simulation and experimental results. Both approaches predict that the half peak width is increased by about $2 \%$ of the Ni-free one for each atomic percent $\mathrm{Ni}$, while the peak temperature is shifted by about $-0.5 \mathrm{~K}$ per atomic percent $\mathrm{Ni}$. However, the simulated decrease of the peak height is almost equal to the experimental one, even though the investigated $\mathrm{Ni}$ compositions are very different. We may infer that the Ni-induced change of the peak height is not linearly dependent on Ni composition. The IF peak height is closely related to the elastic parameters of the material [32]. Recent researches [41, 42] showed that the variation of the elastic properties with the $\mathrm{Ni}$ concentration in alpha-iron is non-linear due to magnetic effects. This elastic behavior should be responsible for the non-linear variation of the peak height with Ni content.

\subsubsection{Comparison with other ferrite systems}

The effect of substitutional solute on the IF profiles have been widely studied in other ferrite systems [11, 12, 43, 44, 22] such as Fe-Cr-C, Fe-Si-C, and Fe-Al-C. The introduction of substitutes $\mathrm{Cr}, \mathrm{Si}, \mathrm{Al}$ in ferrite was reported to lower the Snoek peak, as shown in the present study for the case of $\mathrm{Ni}$. However, the effect of $\mathrm{Cr}, \mathrm{Si}$ and $\mathrm{Al}$ shift the Snoek peak to a higher temperature, while the effect of $\mathrm{Ni}$ is inverse. Ab initio studies on short-range Cr-C [22] and Si-C [45] pair interactions in ferrite revealed that the migration enthalpies of carbons near the substitu- 
tional solutes $\mathrm{Cr}$ and $\mathrm{Si}$ are increased. Even though there is currently no similar $a b$ initio study on the short-range Al-C pair interactions (at least to the authors' knowledge), Strahl et al. deduced from an experiment-based approach that the introduction of $\mathrm{Al}$ increases the overall carbon migration enthalpy [46]. Unlike the above cases, short-range Ni-C pair interactions substantially lower the migration enthalpies of carbon near $\mathrm{Ni}$ atoms [see Fig. 2-(d)]. This difference justifies why the substitutional Ni effect on the temperature shift of the Snoek peak is inverse with respect to those of $\mathrm{Cr}, \mathrm{Si}$, and $\mathrm{Al}$.

\subsection{IF in martensite $\mathrm{Fe}-\mathrm{C}$ and $\mathrm{Fe}-\mathrm{Ni}-\mathrm{C}$}

In martensite $\mathrm{Fe}-\mathrm{C} / \mathrm{Fe}-\mathrm{Ni}-\mathrm{C}$ alloys, carbon atoms are preferentially located at one of the non-equivalent octahedral sites due to elastic interactions between them. The crystal symmetry becomes tetragonal. Conversely to isotropic ferrite, in tetragonal martensite, the crystal response depends on the excitation direction. For an applied shear stress such that $\sigma_{22}=-\sigma_{11}=\sigma_{0} \sin (2 \pi f t)$, we consider two representative cases: (1) the excitation direction is longitudinal to the tetragonal axis of the crystal: the Zener ordering is along the direction 1 or 2; (2) the excitation direction is transverse to the tetragonal axis of the crystal: the Zener ordering is along the direction 3.

\subsubsection{Effect of $C$-C pair interaction on the IF in marten- site $\mathrm{Fe}-\mathrm{C}$ alloy}

Here, we consider the IF profiles in martensite Fe-2C (at.\%). Since the carbon content is relatively high, the validity of the assumption to neglect $\mathrm{C}$-C pair interactions is not trivial. Therefore, in Fig. 3 (top), we compare the IF profiles obtained with and without $\mathrm{C}-\mathrm{C}$ pair interactions.

In the case where $\mathrm{C}-\mathrm{C}$ pair interactions are neglected, both AKMC simulation and TK model are applicable to simulate the Snoek relaxation process. The IF profiles given by these two approaches are in good agreement, except that the peak height obtained from AKMC simulation is slightly $(<5 \%)$ higher than that from TK model. The IF peak height in the case of longitudinal excitation is about 2.5 times larger than that in the case of transverse excitation. Moreover, the peak temperature in the longitudinal case is about $289 \mathrm{~K}$, while the one in the transverse case is about $286 \mathrm{~K}$. Let direction 3 be the Zener ordering direction in the tetragonal martensite. The strain tensor induced by the carbon ordering is $\boldsymbol{\epsilon}_{\mathrm{c}} \simeq[-0.04 \%,-0.04 \%,+1.86 \%]$ in the range of investigated temperatures. Thus, the main contribution of the carbon-induced strain is along the tetragonal axis, i.e., direction 3. The strains induced by the applied excitation is less than $0.1 \%$, which is small compared with the third component of $\boldsymbol{\epsilon}_{\mathrm{c}}$. As mentioned in Section 3.2, if C-C pair interactions are neglected, only 3 non-equivalent migration
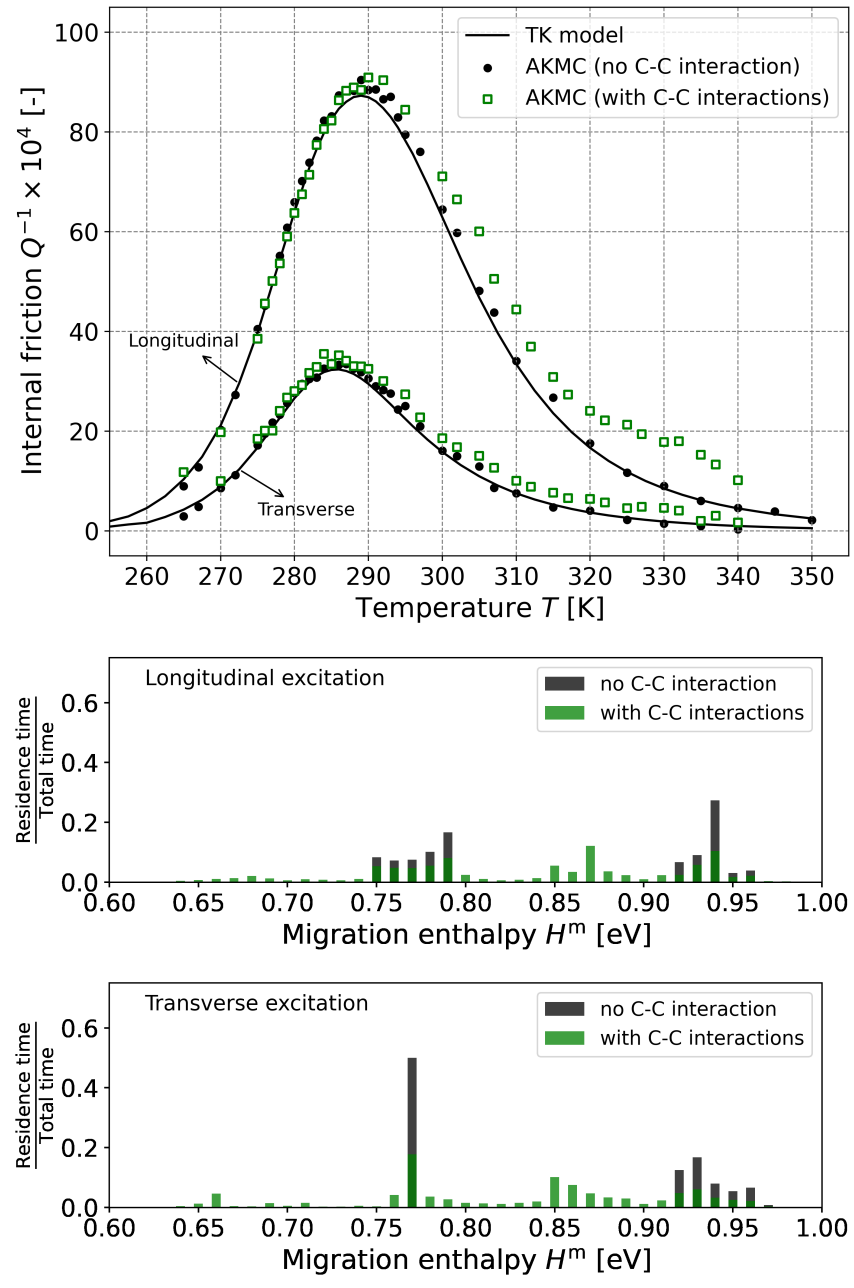

Figure 3: Top: Snoek relaxation profiles in martensite Fe-C. Middle: spectrum of carbon migration enthalpy in martensite Fe-C under longitudinal excitation at $300 \mathrm{~K}$. Bottom: spectrum of carbon migration enthalpy in martensite Fe-C under transverse excitation at $300 \mathrm{~K}$. In the three graphs, the total carbon site fraction $\left(\sum_{i=1}^{3} c_{i}\right)$ is set to 2 at.\% and the oscillation frequency is $1 \mathrm{~Hz}$.

barriers are left:

$$
\begin{aligned}
& H_{1 / 2}^{\mathrm{m}}=H_{0}^{\mathrm{m}}-\left(\boldsymbol{P}_{2}^{\mathrm{T}}-\boldsymbol{P}_{1}^{\mathrm{O}}\right): \boldsymbol{\epsilon}_{\mathrm{c}} \simeq 0.77 \mathrm{eV} \\
& H_{1 / 3}^{\mathrm{m}}=H_{0}^{\mathrm{m}}-\left(\boldsymbol{P}_{3}^{\mathrm{T}}-\boldsymbol{P}_{1}^{\mathrm{O}}\right): \boldsymbol{\epsilon}_{\mathrm{c}} \simeq 0.95 \mathrm{eV} \\
& H_{3 / 1}^{\mathrm{m}}=H_{0}^{\mathrm{m}}-\left(\boldsymbol{P}_{1}^{\mathrm{T}}-\boldsymbol{P}_{3}^{\mathrm{O}}\right): \boldsymbol{\epsilon}_{\mathrm{c}} \simeq 0.94 \mathrm{eV} .
\end{aligned}
$$

The values of these barriers are in good agreement with the migration enthalpy spectrum obtained from AKMC simulation [cf. Fig. 3 (middle and bottom)]. Since $H_{1 / 3}^{\mathrm{m}}$ and $H_{3 / 1}^{\mathrm{m}}$ are almost equal, their enthalpy peaks are overlapped in the spectrum. Since the IF profiles can be well reproduced by a fit of Debye equation (7), we may assume that the IF is mostly controlled by one of the three jumps. Each jump represents only $1 / 3$ of all the possible jumps, we replace ' $6 \nu_{0}$ ' by ' $2 \nu_{0}$ ' in Eq. (9) to obtain the peak temperature related to $H_{1 / 2}^{\mathrm{m}}, H_{1 / 3}^{\mathrm{m}}$ and $H_{3 / 1}^{\mathrm{m}}$, which are given to be $286 \mathrm{~K}, 349 \mathrm{~K}$ and $347 \mathrm{~K}$, respectively. The temperature related to $H_{1 / 2}^{\mathrm{m}}$ corresponds well to the peak 
Table 2: Ni-alloying-induced changes of the internal friction profile parameters obtained from the reported studies in Ref. [19] (Fe-5Ni$0.07 \mathrm{C} / \mathrm{Fe}-0.07 \mathrm{C})$ and the present work (Fe-25Ni-0.01C/Fe-0.01C).

\begin{tabular}{lcc}
\hline \hline Alloys in comparison & Fe-25Ni-0.01C/Fe-0.01C & Fe-5Ni-0.07C/Fe-0.07C \\
\hline $\begin{array}{l}\text { Peak height change with respect to the } \\
\text { Ni-free peak height }(\%)\end{array}$ & $-40[-1.6 /($ at. $\% \mathrm{Ni})]$ & $-40[-8.0 /(\mathrm{at} . \% \mathrm{Ni})]$ \\
$\begin{array}{l}\text { Peak width change with respect to the } \\
\text { Ni-free peak width }(\%)\end{array}$ & $+60[+2.4 /($ at. $\% \mathrm{Ni})]$ & $+11[+2.2 /(\mathrm{at} . \% \mathrm{Ni})]$ \\
$\begin{array}{l}\text { Peak temperature shift with respect to } \\
\text { the Ni-free peak temperature }(\mathrm{K})\end{array}$ & $-10[-0.40 /(\mathrm{at} . \% \mathrm{Ni})]$ & $-2.7[-0.54 /(\mathrm{at} . \% \mathrm{Ni})]$ \\
\hline \hline
\end{tabular}

temperature in the transverse case, but slightly lower than the one in the longitudinal case. From this, we can infer that the jump $\omega_{1 / 2}$ has a major contribution to the IF in martensite Fe-C, while the contributions of jumps $\omega_{1 / 3}$ and $\omega_{3 / 1}$ should be much smaller. Note that in the longitudinal case, excitation is applied in the Zener ordering direction, leading to a fluctuation of the order parameter and the carbon-induced strain $\left(\epsilon_{3} \simeq 1.86 \% \pm 0.10 \%\right)$. Due to this fluctuation, the migration enthalpy fluctuates around $H_{1 / 2}^{\mathrm{m}}$ in the longitudinal case, and the fluctuation is about $\pm 0.3 \mathrm{eV}$, corresponding well to the migration enthalpy spectrum. Therefore, the IF peak temperature in the case of longitudinal excitation does not exactly correspond to $H_{1 / 2}^{\mathrm{m}}$.

Considering now the migration enthalpy spectrum obtained from AKMC simulations with C-C pair interactions, there are more possible values of the migration enthalpy apart of $H_{1 / 2}^{\mathrm{m}}(0.77 \mathrm{eV}), H_{1 / 3}^{\mathrm{m}}(0.95 \mathrm{eV})$ and $H_{3 / 1}^{\mathrm{m}}$ $(0.94 \mathrm{eV})$. An additional enthalpy peak occurs at about $0.86 \mathrm{eV}$. However, this additional enthalpy peak does not result in a very different $\mathrm{IF}$ profile compared with the one obtained from neglecting $\mathrm{C}-\mathrm{C}$ pair interactions. The introduction of $\mathrm{C}-\mathrm{C}$ pair interaction leads to a slight increase $(<15 \%)$ of the IF at $T<310 \mathrm{~K}$, while a greater increase up to $100 \%$ at $T>310 \mathrm{~K}$. Note that including C-C pair interaction hardly changes the peak at about $286 \mathrm{~K}$. This result should remain correct when the carbon content is lower than 2 at.\%. However, C-C pair interactions lead to a new peak at between $320 \mathrm{~K}$ and $330 \mathrm{~K}$ due to the additional enthalpy peak at about $0.86 \mathrm{eV}$.

\subsubsection{Ni-alloying effect on the IF in martensite Fe-C alloy}

Including C-C pair interactions sharply increases the computational cost of the AKMC simulations, whereas it has only slight effect on the resulting IF profiles in $\mathrm{Fe}-2 \mathrm{C}$ at most investigated temperatures $(T<310 \mathrm{~K})$, as shown in the previous section. Therefore, we neglect $\mathrm{C}-\mathrm{C}$ pair interactions and consider only $\mathrm{Ni}-\mathrm{C}$ pair interactions in the calculation of IF profile in $\mathrm{Fe}-25 \mathrm{Ni}-2 \mathrm{C}$.

In Fig. 4 (top), we compare the simulated IF profiles in Fe-2C and Fe-25Ni-2C. In both longitudinal and transverse cases, the introduction of 25 at. $\%$ Ni leads to two peaks in the IF profile: one at lower temperature $(\sim 275 \mathrm{~K})$ with
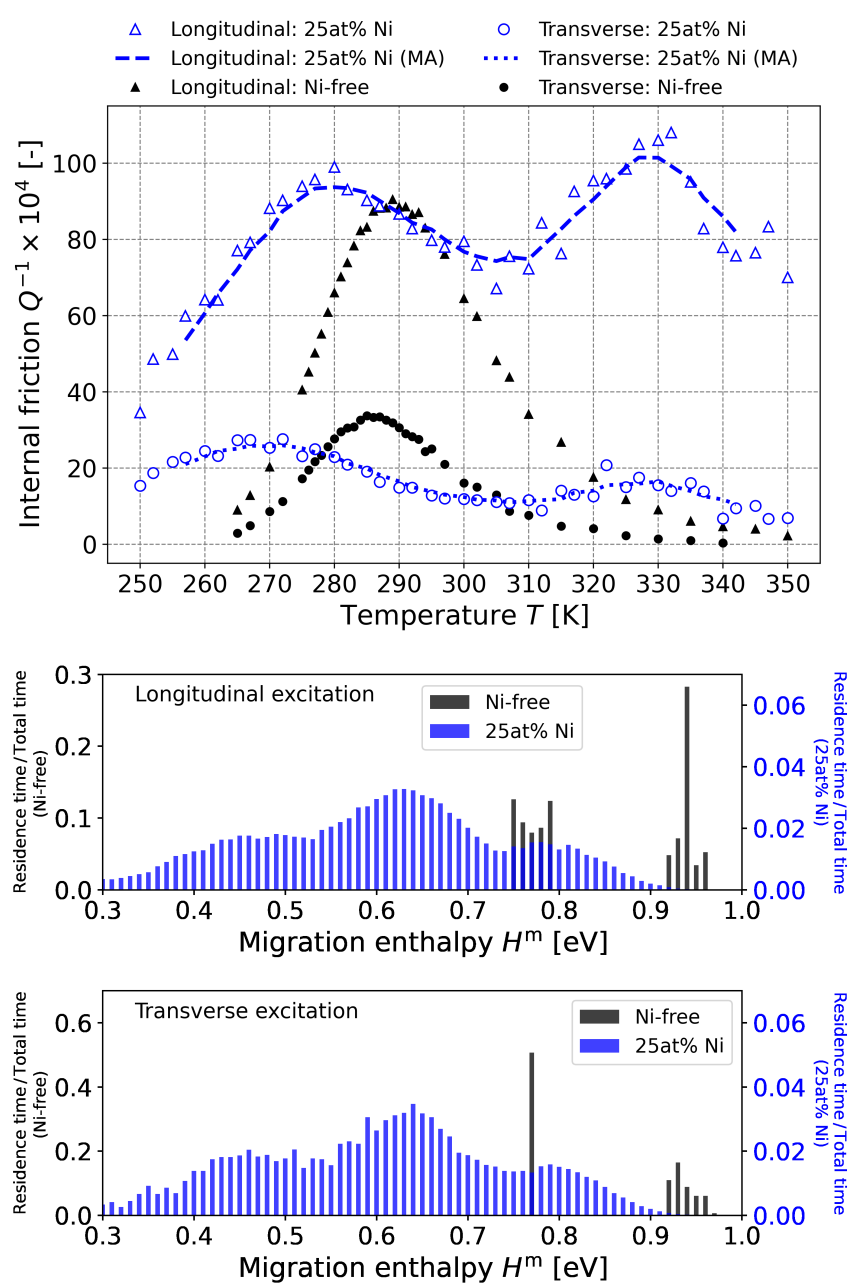

Figure 4: Top: Snoek relaxation profiles in martensite Fe-C (filled points) and Fe-Ni-C (unfilled points). The moving average (MA) of the results in $\mathrm{Fe}-\mathrm{Ni}-\mathrm{C}$ are also presented (dashed and dotted lines). Middle: spectrum of carbon migration enthalpy in martensite Fe$\mathrm{Ni}-\mathrm{C}$ under longitudinal excitation at $300 \mathrm{~K}$. Bottom: spectrum of carbon migration enthalpy in martensite $\mathrm{Fe}-\mathrm{Ni}-\mathrm{C}$ under transverse excitation at $300 \mathrm{~K}$. In the three graphs, the total carbon site fraction $\left(\sum_{i=1}^{3} c_{i}\right)$ is set to 2 at.\%, the $\mathrm{Ni}$ site fraction in $\mathrm{Fe}-\mathrm{Ni}-\mathrm{C}$ is set to 25 at.\%, and the oscillation frequency is $1 \mathrm{~Hz}$.

respect to the peak in $\mathrm{Fe}-2 \mathrm{C}$, and the other one at higher temperature $(\sim 330 \mathrm{~K})$. 
As shown in previous sections, the IF behaviors are closely related to the atomic migration mechanisms. According to Fig. 4 (middle and bottom), the alloying of 25 at.\% Ni completely changes the spectrum of the migration enthalpy extracted from the AKMC simulation. The spectrum is shifted to lower enthalpy because the repulsive Ni-C interaction lowers the carbon migration barriers. Moreover, three smooth peaks occur in the enthalpy spectrum of Fe-25Ni-2C, unlike the one of Fe-2C consisting of two sharp peaks. The appearance of the three enthalpy peaks in martensite $\mathrm{Fe}-25 \mathrm{Ni}-2 \mathrm{C}$ is related to the strain induced by carbon ordering. Let direction 3 be the Zener ordering direction. The carbon-induced strain tensor is $\boldsymbol{\epsilon}_{\mathrm{c}}=[-0.4 \%,-0.4 \%,+2.3 \%]$. This strain modifies the two enthalpy peaks $\left(H^{\text {near }} \simeq 0.60 \mathrm{eV}\right.$ and $\left.H^{\text {far }} \simeq 0.77 \mathrm{eV}\right)$ in Fe-25Ni alloy [cf. Fig. 2-(b)], corresponding respectively to the carbon migration enthalpies near and far from $\mathrm{Ni}$ atoms. In the presence of the strain field, we consider the following six non-equivalent migration barriers:

$$
\begin{aligned}
& H_{1 / 2}^{\text {near }}=H^{\text {near }}-\left(\boldsymbol{P}_{2}^{\mathrm{T}}-\boldsymbol{P}_{1}^{\mathrm{O}}\right): \boldsymbol{\epsilon}_{\mathrm{c}} \simeq 0.47 \mathrm{eV} \\
& H_{1 / 3}^{\text {near }}=H^{\text {near }}-\left(\boldsymbol{P}_{3}^{\mathrm{T}}-\boldsymbol{P}_{1}^{\mathrm{O}}\right): \boldsymbol{\epsilon}_{\mathrm{c}} \simeq 0.66 \mathrm{eV} \\
& H_{3 / 1}^{\text {near }}=H^{\text {near }}-\left(\boldsymbol{P}_{1}^{\mathrm{T}}-\boldsymbol{P}_{3}^{\mathrm{O}}\right): \boldsymbol{\epsilon}_{\mathrm{c}} \simeq 0.66 \mathrm{eV} \\
& H_{1 / 2}^{\text {far }}=H^{\text {far }}-\left(\boldsymbol{P}_{2}^{\mathrm{T}}-\boldsymbol{P}_{1}^{\mathrm{O}}\right): \boldsymbol{\epsilon}_{\mathrm{c}} \simeq 0.64 \mathrm{eV} \\
& H_{1 / 3}^{\text {far }}=H^{\text {far }}-\left(\boldsymbol{P}_{3}^{\mathrm{T}}-\boldsymbol{P}_{1}^{\mathrm{O}}\right): \boldsymbol{\epsilon}_{\mathrm{c}} \simeq 0.83 \mathrm{eV} \\
& H_{3 / 1}^{\text {far }}=H^{\text {far }}-\left(\boldsymbol{P}_{1}^{\mathrm{T}}-\boldsymbol{P}_{3}^{\mathrm{O}}\right): \boldsymbol{\epsilon}_{\mathrm{c}} \simeq 0.83 \mathrm{eV} .
\end{aligned}
$$

We have roughly three different values for these six migration enthalpies: $0.47 \mathrm{eV}\left(H_{1 / 2}^{\text {near }}\right), \sim 0.65 \mathrm{eV}\left(H_{1 / 3}^{\text {near }}, H_{3 / 1}^{\text {near }}\right.$, and $\left.H_{1 / 2}^{\text {far }}\right)$, and $0.83 \mathrm{eV}\left(H_{1 / 3}^{\text {far }}\right.$ and $\left.H_{3 / 1}^{\text {far }}\right)$. These three values, corresponding well to the three enthalpy peaks, justify the shape of the enthalpy spectrum. The $0.65 \mathrm{eV}$ and $0.83 \mathrm{eV}$ enthalpy peaks are related respectively to the $275 \mathrm{~K}$ and $330 \mathrm{~K}$ IF peaks. A third IF peak, related to the $0.47 \mathrm{eV}$ enthalpy peak, may occur at very low temperature $(<250 \mathrm{~K})$. As mentioned in Section 4.1.2, the simulation of IF measurement was not performed at such low temperature due to unrealistic computational cost.

\subsubsection{Discussion on the experiment in martensite}

Experimental IF profiles of martensites have been reported to contain multiple peaks $[47,9,48,49,50,51]$. The identification of the relaxation process related to each IF peak is not yet well established [52]. Dislocation density is relatively high in martensites. It is in general difficult to capture the Snoek peak in the IF profile because its amplitude could be much smaller than those related to carbondislocation interaction [32], as for instance the dislocationenhanced Snoek peak and the Snoek-Kê-Köster peak [53]. Moreover, it is challenging to identify and quantitatively compare reported IF profiles as they were usually obtained from different excitation frequencies. Only a few studies reported the existence of a potential Snoek peak in martensites. Prioul [47] showed a Snoek-like peak at about $253 \mathrm{~K}$ in $\mathrm{Fe}-29 \mathrm{Ni}-0.8 \mathrm{C}$ (at.\%) obtained by an excitation frequency of $1.5 \mathrm{~Hz}$. Liu [9] reported a similar Snoek-like peak at about $255 \mathrm{~K}$ in $\mathrm{Fe}-29 \mathrm{Ni}-0.9 \mathrm{C}$ for $1 \mathrm{~Hz}$ excitation frequency. Both reported peak temperatures are lower than the simulated one in Fe-25Ni-2C $(\sim 275 \mathrm{~K})$ for $1 \mathrm{~Hz}$ test frequency. This difference may be due to the higher $\mathrm{Ni}$ content in the experimental alloys than the simulated one. Moreover, the dislocation stress and the coherency stress, which were not considered in the present model, may also lead to this discrepancy.

\section{Conclusions}

This work provides a quantitative simulation of the Snoek-like internal friction (IF) in ferrite and martensite Fe-C and Fe-Ni-C model alloys. The carbon thermodynamics and kinetics are described by a mean-field elastic model. The Snoek relaxation process is simulated by a thermo-kinetic model for specific systems ( $\mathrm{Fe}-\mathrm{C}$ alloys) and by atomistic kinetic Monte Carlo for general systems. We summarize below the most relevant results obtained from the present study.

- $\mathrm{C}-\mathrm{C}$ and $\mathrm{Ni}-\mathrm{C}$ pair interactions lead to additional peaks in the IF profile of $\mathrm{Fe}-\mathrm{C}$ and $\mathrm{Fe}-\mathrm{Ni}-\mathrm{C}$ alloys.

- In ferrite or martensite Fe-Ni-C, the carbon migration barrier is composition-sensitive due to the $\mathrm{Ni}-\mathrm{C}$ pair interaction. The resulting peak of the IF profile is not simply related to the most frequent carbon jump.

- Our simulations show that the alloying of 25 at.\% Ni lowers the IF amplitude and the peak temperature in ferrite Fe-0.01C. This tendency qualitatively corresponds well to experimental results.

- Unlike the IF behaviors in ferrite, the ones in martensite depend on the excitation direction. Under a longitudinal excitation affecting the carbon ordering, the IF amplitude is higher than the one obtained from a transverse excitation that barely changes the carbon ordering.

For a more complete study of the IF behaviors, the interaction of carbon atoms with dislocations should be included in the present model. Moreover, carbon segregation and clustering, resulting in non-uniform elastic field that affects the carbon diffusion and IF behaviors, should also be accounted for. These points are left for future works.

\section{Acknowledgments}

This work was supported by the Agence Nationale de la Recherche (contract C-TRAM ANR-18-CE92-0021). Aix-Marseille mesocentre and CPPM computing department are acknowledged for granting access to their highperformance computing resources. 


\section{Data availability}

The authors confirms that the data supporting the findings of this study are available within the article. Raw data that support the findings of this study are available from the corresponding author, upon reasonable request.

\section{References}

[1] N.-q. Zhu, L. Lu, Y.-l. He, L. Li, X.-g. Lu, Coarsening of M23C6 Precipitates in an Fe-Cr-C Ternary Alloy, J. Iron Steel Res. Int. 19 (9) (2012) 62-67. doi:10.1016/S1006-706X (13)60009-6.

URL http://link.springer.com/10.1016/S1006-706X(13) 60009-6

[2] D. Bouchet, L. Priester, Indirect detection of grain-boundary segregation of carbon in iron-chromium alloys (Cr 10electrochemical study, J. Mater. Sci. 14 (9) (1979) 2205-2214. doi: $10.1007 / \mathrm{BF} 00688427$.

URL http://link.springer.com/10.1007/BF00688427

[3] B. Lüthi, F. Berthier, L. Ventelon, B. Legrand, D. Rodney, F. Willaime, Ab initio thermodynamics of carbon segregation on dislocation cores in bcc iron, Model. Simul. Mater. Sci. Eng. 27 (7) (2019) 074002. arXiv:NIHMS150003, doi:10.1088/1361-651X/ab28d4.

URL https://iopscience.iop.org/article/10.1088/ 1361-651X/ab28d4

[4] I. S. Golovin, V. I. Sarrak, S. O. Suvorova, Influence of carbon and nitrogen on solid solution decay, Metall. Trans. A 23 (9) (1992) 2567-2579. doi:10.1007/BF02658060. URL http://link.springer.com/10.1007/BF02658060

[5] G. Krauss, Martensite in steel: strength and structure, Mater. Sci. Eng. A 273-275 (1999) 40-57. doi:10.1016/S0921-5093(99)00288-9.

URL https://linkinghub.elsevier.com/retrieve/pii/ S0921509399002889

[6] J. van der Laan, P. Willemse, J. Klostermann, Internal friction measurements in iron-nickel-carbon alloys, Scr. Metall. 7 (1) (1973) 81-88. doi:10.1016/0036-9748(73) 90186-5.

URL https://linkinghub.elsevier.com/retrieve/pii/ 0036974873901865

[7] G. J. Klems, R. E. Miner, F. A. Hultgren, R. Gibala, Internal friction in ferrous martensites, Metall. Trans. A 7 (6) (1976) 839-849. doi:10.1007/BF02644081. URL http://link.springer.com/10.1007/BF02644081

[8] C. De A. Rodrigues, C. Prioul, Internal friction and dilatometric quantitative analysis of the isothermal martensitic transformation in Fe-Ni-C alloys, Le J. Phys. Colloq. 46 (C10) (1985) C10-657-C10-660. doi:10.1051/jphyscol:198510145. URL http://www.edpsciences.org/10.1051/jphyscol: 198510145

[9] Y. Liu, Internal friction associated with dislocation relaxations in virgin martensite-I. Experiments, Acta Metall. Mater. 41 (11) (1993) 3277-3287. doi: 10.1016/0956-7151(93) 90057-Y.

URL https://linkinghub.elsevier.com/retrieve/pii/ $095671519390057 \mathrm{Y}$

[10] Y. Liu, Internal friction associated with dislocation relaxations in virgin martensite - II. Interpretation, Acta Metall. Mater. 42 (3) (1994) 621-630. doi:10.1016/0956-7151(94)90258-5. URL https://linkinghub.elsevier.com/retrieve/pii/ 0956715194902585

[11] I. S. Golovin, M. S. Blanter, R. Schaller, Snoek Relaxation in $\mathrm{Fe}-\mathrm{Cr}$ Alloys and Interstitial-Substitutional Interaction, Phys. status solidi 160 (1) (1997) 49-60. doi:10.1002/ 1521-396X (199703) $160: 1<49:$ : AID-PSSA49>3.0.CD;2-P. URL https://onlinelibrary.wiley.com/doi/10.1002/ 1521-396X (199703) $160: 1 \% 3 C 49:$ : AID-PSSA49\%3E3.0.CD;2-P

[12] H. Saitoh, N. Yoshinaga, K. Ushioda, Influence of substitutional atoms on the Snoek peak of carbon in b.c.c. iron, Acta
Mater. 52 (5) (2004) 1255-1261. doi:10.1016/j.actamat. 2003. 11.009.

[13] M. J. Konstantinović, W. V. Renterghem, M. Matijašević, B. Minov, M. Lambrecht, T. Toyama, M. Chiapetto, L. Malerba, Mechanical and microstructural properties of neutron irradiated $\mathrm{Fe}-\mathrm{Cr}-\mathrm{C}$ alloys, Phys. Status Solidi Appl. Mater. Sci. 213 (11) (2016) 2988-2994. doi:10.1002/pssa.201600316.

[14] C. Zener, Theory of Strain Interaction of Solute Atoms, Phys. Rev. 74 (6) (1948) 639-647. doi:10.1103/PhysRev.74.639. URL https://link.aps.org/doi/10.1103/PhysRev.74.639

[15] J. Snoek, Effect of small quantities of carbon and nitrogen on the elastic and plastic properties of iron, Physica 8 (7) (1941) 711-733. doi:10.1016/S0031-8914(41)90517-7.

URL https://linkinghub.elsevier.com/retrieve/pii/ S0031891441905177

[16] C. Zener, Elasticity and Anelasticity of Metals, Chicago University Committee on Publications in the Physical Sciences, University of Chicago Press, 1948.

URL https://books.google.fr/books?id=FKcZAAAAIAAJ

[17] H. Numakura, M. Koiwa, The Snoek Relaxation in Dilute Ternary bcc Alloys. A Review, Le J. Phys. IV 06 (C8) (1996) C8-97-C8-106. doi:10.1051/jp4:1996819. URL http://www.edpsciences.org/10.1051/jp4:1996819

[18] A. P. Mouritz (Ed.), Introduction to Aerospace Materials, 1st Edition, Woodhead Publishing, 2012.

[19] D. Hasson, R. Arsenault, Substitutional-Interstitial Interactions in bcc Alloys, in: Treatise Mater. Sci. Technol., Princeton University Press, 1972, pp. 179-246. doi:10.1016/B978-0-12-341801-2.50009-6.

URL https://www.degruyter.com/document/doi/10.1515/ 9781400832460-013/htmlhttps://linkinghub.elsevier.com/ retrieve/pii/B9780123418012500096

[20] P. Maugis, Giant Snoek peak in ferrite due to carbon-carbon strain interactions, Materialia 12 (April) (2020) 100805. doi:10.1016/j.mtla.2020.100805.

URL https://linkinghub.elsevier.com/retrieve/pii/ S2589152920302210

[21] P. Maugis, Thermo-kinetic modelling of the giant Snoek effect in carbon-supersaturated iron, Journal of Alloys and Compounds 877 (2021) 160236. doi:10.1016/j.jallcom.2021.160236. URL https://linkinghub.elsevier.com/retrieve/pii/ S0925838821016455

[22] R. Herschberg, C.-C. Fu, M. Nastar, F. Soisson, Atomistic modelling of the diffusion of $\mathrm{C}$ in $\mathrm{Fe}$ Cr alloys, Acta Materialia 165 (2019) 638-653. doi:10.1016/j.actamat.2018.11.025. URL https://doi.org/10.1016/j.actamat.2018.11. 025https://linkinghub.elsevier.com/retrieve/pii/ S1359645418309017

[23] P. Maugis, Ferrite, martensite and supercritical iron: A coherent elastochemical theory of stress-induced carbon ordering in steel, Acta Materialia 158 (2018) 454-465. doi: $10.1016 / j$.actamat .2018 .08 .001 .

URL https://doi.org/10.1016/j.actamat.2018.08. 001https://linkinghub.elsevier.com/retrieve/pii/ S1359645418306256

[24] P. Maugis, S. Chentouf, D. Connétable, Stress-controlled carbon diffusion channeling in bct-iron: A meanfield theory, J. Alloys Compd. 769 (2018) 1121-1131. doi:10.1016/j.jallcom.2018.08.060.

URL https://linkinghub.elsevier.com/retrieve/pii/ S0925838818329335

[25] A. Khachaturyan, G. Shatalov, On the theory of the ordering of carbon atoms in a martensite crytal, Physics of Metals and Metallography 32 (1971) 1-9.

[26] C. Varvenne, F. Bruneval, M.-C. Marinica, E. Clouet, Point defect modeling in materials: Coupling ab initio and elasticity approaches, Physical Review B 88 (13) (2013) 134102. doi:10.1103/PhysRevB.88.134102.

URL https://link.aps.org/doi/10.1103/PhysRevB.88. 134102

[27] B. Lawrence, C. W. Sinclair, M. Perez, Carbon diffusion 
in supersaturated ferrite: a comparison of mean-field and atomistic predictions, Model. Simul. Mater. Sci. Eng. 22 (6) (2014) 065003. doi:10.1088/0965-0393/22/6/065003.

URL https://iopscience.iop.org/article/10.1088/ 0965-0393/22/6/065003

[28] E. Clouet, C. Varvenne, T. Jourdan, Elastic modeling of pointdefects and their interaction, Comput. Mater. Sci. 147 (2018) 49-63. arXiv:1802.04062, doi:10.1016/j.commatsci.2018. 01.053.

URL https://doi.org/10.1016/j.commatsci.2018.01.053

[29] D. Kandaskalov, L. Huang, J. Emo, P. Maugis, Carbon diffusion in bcc- and bct-Fe: influence of short-range $\mathrm{C}-\mathrm{C}$ interactions studied from first-principles calculations, submitted.

[30] P. Eyméoud, L. Huang, P. Maugis, Impact of Ni alloying on Fe-C martensite ageing: an atomistic investigation, Scr. Mater. 205 (2021) 114182. doi:10.1016/j.scriptamat.2021.114182. URL https://linkinghub.elsevier.com/retrieve/pii/ $\mathrm{S} 1359646221004620$

[31] J. da Silva, R. B. McLellan, Diffusion of carbon and nitrogen in B.C.C. iron, Materials Science and Engineering 26 (1) (1976) 83-87. doi:10.1016/0025-5416(76)90229-9.

URL https://linkinghub.elsevier.com/retrieve/pii/ 0025541676902299

[32] A. S. Nowick, B. Berry, Anelastic Relaxation in Crystalline Solids, Elsevier, 1972. doi:10.1016/B978-0-12-522650-9. X5001-0.

URL https://linkinghub.elsevier.com/retrieve/pii/ B9780125226509X50010

[33] M. Weller, The Snoek relaxation in bcc metals-From steel wire to meteorites, Materials Science and Engineering: A 442 (1-2) (2006) 21-30. doi:10.1016/j.msea.2006.02.232. URL https://linkinghub.elsevier.com/retrieve/pii/ S092150930601166X

[34] G. Cacciamani, A. Dinsdale, M. Palumbo, A. Pasturel, The Fe-Ni system: Thermodynamic modelling assisted by atomistic calculations, Intermetallics 18 (6) (2010) 1148-1162. doi:10.1016/j.intermet.2010.02.026.

URL http://www.sciencedirect.com/science/article/ pii/S0966979510001020https://linkinghub.elsevier.com/ retrieve/pii/S0966979510001020

[35] E. A. Wilson, $\gamma \rightarrow \alpha$ transformation in Fe, Fe-Ni, and $\mathrm{Fe}-\mathrm{Cr}$ alloys, Met. Sci. 18 (10) (1984) 471-484. doi:10.1179/030634584790253155.

URL http://www.tandfonline.com/doi/full/10.1179/ 030634584790253155

[36] L. J. Swartzendruber, V. P. Itkin, C. B. Alcock, The Fe-Ni (iron-nickel) system, J. Phase Equilibria 12 (3) (1991) 288-312. doi: 10.1007/BF02649918.

URL

http://link.springer.com/10.1007/ 978-0-387-72264-1_19http://link. springer.com/10.1007/ BF02649918

[37] A. Borgenstam, M. Hillert, Driving force for f.c.c. $\rightarrow$ b.c.c. martensites in Fe-X alloys, Acta Mater. 45 (5) (1997) 2079 2091. doi:10.1016/S1359-6454(96)00308-4.

URL http://ac.els-cdn.com/S1359645496003084/ 1-s2.0-S1359645496003084-main.pdf?_tid= $55975 \mathrm{f} 1 \mathrm{a}-243 \mathrm{c}-11 \mathrm{e} 7-\mathrm{a} 3 \mathrm{e} 6-00000 \mathrm{aacb} 35 \mathrm{~d} \& \mathrm{acdnat}=$ 1492522901_decf7aeb992a941eab9bb3e3417d4756https : // linkinghub.elsevier.com/retrieve/pii/S1359645496003084

[38] H. Ino, S. Takagi, T. Sugeno, On the relaxation strength of the snoek peak, Acta Metallurgica 15 (1) (1967) 29-34. doi:10.1016/0001-6160(67)90152-6.

URL https://linkinghub.elsevier.com/retrieve/pii/ 0001616067901526

[39] M. Koiwa, Theory of the snoek effect in ternary b.c.c. alloysI. General theory, Philos. Mag. 24 (187) (1971) 81-106. doi : 10.1080/14786437108216426.

URL http://www.tandfonline.com/doi/abs/10.1080/ 14786437108216426

[40] M. Koiwa, Theory of the snoek effect in ternary b.c.c. alloysII. Simplified treatment, Philos. Mag. 24 (187) (1971) 107-122. doi:10.1080/14786437108216427.

URL http://www.tandfonline.com/doi/abs/10.1080/ 14786437108216427

[41] P. Eyméoud, P. Maugis, Magnetic behavior of transition metal solutes in $\alpha$-iron: a classification, J. Magn. Magn. Mater. 513 (2020) 167223. doi:10.1016/j.jmmm.2020.167223.

URL https://linkinghub.elsevier.com/retrieve/pii/ S0304885320311902

[42] P. Eyméoud, D. Kandaskalov, P. Maugis, Impact of stresses and alloying elements on ferrous martensite nanodomains, submitted.

[43] I. S. Golovin, H. Neuhäuser, A. Rivière, A. Strahl, Anelasticity of Fe-Al alloys, revisited, Intermetallics 12 (2) (2004) 125-150. doi:10.1016/j.intermet.2003.10.003.

[44] I. S. Golovin, S. Jäger, V. A. Semin, G. V. Serzhantova, H. R. Sinning, O. A. Sokolova, F. Stein, S. A. Golovin, Snoek-type and Zener relaxation in Fe-Si-Al Alloys, Solid State Phenom. 137 (2008) 69-82. doi:10.4028/www.scientific.net/SSP.137.69.

[45] D. Simonovic, C. K. Ande, A. I. Duff, F. Syahputra, M. H. F. Sluiter, Diffusion of carbon in bcc Fe in the presence of Si, Phys. Rev. B 81 (5) (2010) 054116. doi:10.1103/PhysRevB.81.054116.

URL https://link.aps.org/doi/10.1103/PhysRevB.81. 054116

[46] A. Strahl, I. Golovin, H. Neuhäuser, S. Golovina, H.-R. Sinning, Influence of $\mathrm{Al}$ concentration on the short-range and long-range diffusion of carbon in Fe-Al alloys, Mater. Sci. Eng. A 442 (1-2) (2006) 128-132. doi:10.1016/j.msea.2006.05.160.

URL https://linkinghub.elsevier.com/retrieve/pii/ S0921509306010446

[47] C. Prioul, Snoek like relaxation in Fe-Ni-C virgin martensite, Le J. Phys. Colloq. 46 (C10) (1985) C10-665-C10-668. doi:10.1051/jphyscol:198510147.

URL http://www.edpsciences.org/10.1051/jphyscol: 198510147

[48] R. Bagramov, D. Mari, W. Benoit, Internal friction in a martensitic high-carbon steel, Philos. Mag. A 81 (12) (2001) 2797-2808. doi:10.1080/01418610108217165.

URL http://www.tandfonline.com/doi/abs/10.1080/ 01418610108217165

[49] I. Tkalcec, D. Mari, Internal friction in martensitic, ferritic and bainitic carbon steel; cold work effects, Mater. Sci. Eng. A 370 (1-2) (2004) 213-217. doi:10.1016/j.msea.2003.04.004.

[50] J. J. Hoyos, A. A. Ghilarducci, D. Mari, Evaluation of dislocation density and interstitial carbon content in quenched and tempered steel by internal friction, Mater. Sci. Eng. A 640 (2015) 460-464. doi:10.1016/j.msea.2015.06.025. URL http://dx.doi.org/10.1016/j.msea.2015.06.025

[51] W. S. Choi, J. Lee, B. C. De Cooman, Internal-friction analysis of dislocation-interstitial carbon interactions in press-hardened 22MnB5 steel, Mater. Sci. Eng. A 639 (2015) 439-447. doi: 10.1016/j.msea.2015.05.055. URL http://dx.doi.org/10.1016/j.msea.2015.05.055

[52] D. H. Sulistiyo, L. Cho, E. J. Seo, B. C. De Cooman, Internal friction analysis of lath martensite in press hardened steel, Mater. Sci. Technol. 33 (7) (2017) 879-892. doi: $10.1080 / 02670836.2016 .1244151$.

URL https://www.tandfonline.com/doi/full/10.1080/ 02670836.2016.1244151

[53] M. S. Blanter, I. S. Golovin, H. Neuhäuser, H.-R. Sinning, Internal Friction in Metallic Materials, Vol. 90 of Springer Series in Materials Science, Springer Berlin Heidelberg, Berlin, Heidelberg, 2007. doi:10.1007/978-3-540-68758-0.

URL http://link.springer.com/10.1007/ 